\title{
Close association of severe hyponatremia with exaggerated release of arginine vasopressin in elderly subjects with secondary adrenal insufficiency
}

\author{
Toshimitsu Yatagai $^{1}$, Ikuyo Kusaka ${ }^{1}$, Tomoatsu Nakamura ${ }^{1}$, Shoichiro Nagasaka ${ }^{1}$, Kazufumi Honda ${ }^{1}$, \\ Shun Ishibashi ${ }^{1}$ and San-e Ishikawa ${ }^{1,2}$ \\ ${ }^{1}$ Division of Endocrinology and Metabolism, Department of Medicine, Jichi Medical School, Tochigi 329-0498, Japan and ${ }^{2}$ Department of Medicine, \\ Jichi Medical School, Omiya Medical Center, Saitama 330-8503, Japan \\ (Correspondence should be addressed to San-e Ishikawa, Department of Medicine, Jichi Medical School, Omiya Medical Center, 1-847 Amanuma, Saitama
} 330-8503, Japan; Email: saneiskw@jichi.ac.jp)

\begin{abstract}
Objective: Hyponatremia occurs not infrequently in hypopituitarism. Arginine vasopressin (AVP)induced impaired water excretion is found in patients with hypopituitarism and experimental models of glucocorticoid deficiency.

Design: The present study was undertaken to determine whether augmented release of AVP is involved in the development of hyponatremia in elderly subjects with secondary adrenal insufficiency. Methods: Forty patients with ACTH-deficient, secondary adrenal insufficiency were examined. They were divided into three groups according to the age at which diagnosis was ascertained (group A $<20$ years, group B $20-64$ years, and group $C \geq 65$ years).

Results: Hyponatremia was more manifest in the elderly group than in the other two groups, serum sodium (Na) levels being $124.7 \mathrm{mmol} / \mathrm{l}$ in the elderly group, a value significantly less than 141.5 and $133.5 \mathrm{mmol} / \mathrm{l}$ in groups A and B. Plasma AVP levels seemed likely to be high compared with the respective hypo-osmolality in plasma in the elderly group, as plasma AVP levels were $1.7 \mathrm{pmol} / \mathrm{l}$ despite a mean plasma osmolality of $259 \mathrm{mmol} / \mathrm{kg}$. Such an alteration was less clear in group B and was not found in group A. Therefore, elevation of plasma AVP was apparent in the elderly patients. Hydrocortisone replacement promptly normalized serum $\mathrm{Na}$ levels from 125 to $142 \mathrm{mmol} / \mathrm{l}(P<0.01)$ and reduced plasma AVP levels from 1.7 to $0.9 \mathrm{pmol} / \mathrm{l}(P<0.05)$, which were comparable to the respective plasma osmolality in the elderly patients.

Conclusion: These results indicate that non-suppressible release of AVP is crucially involved in the impaired water excretion and hyponatremia seen in elderly patients with secondary adrenal insufficiency compared with the younger patients, and that exaggerated release of AVP becomes manifest as the subjects grow older.
\end{abstract}

European Journal of Endocrinology 148 221-226

\section{Introduction}

Hyponatremia occurs, not infrequently, in elderly subjects who are usually asymptomatic. As described previously (1), hyponatremia of less than $130 \mathrm{mmol} / \mathrm{l}$ is classified into a category of euvolemic hyponatremia in elderly subjects who are aged 65 years or older, and approximately $40 \%$ of the severe hyponatremia is derived from hypopituitarism, particularly hypofunction of the pituitary and adrenocortical axis. There has been an important debate since the $1950 \mathrm{~s}$ regarding the mechanisms for hyponatremia in adrenal insufficiency, that is, whether water retention or renal deficit of sodium $(\mathrm{Na})$ is more prominent in producing hyponatremia $(2-6)$. Studies performed in isolated glucocorticoid deficiency showed that impaired water excretion occurred in the patients with hypopituitarism and in experimental models of glucocorticoid deficiency (3, 5-10). Non-suppressible release of arginine vasopressin (AVP) was found despite hypo-osmolality which should suppress AVP release to undetectable levels $(3,6,7,11)$. In addition, the expression of aquaporin-2 (AQP-2) water channel mRNA and protein in kidney was upregulated in glucocorticoid-deficient rats (12). Hydrocortisone replacement corrected the defect in renal water excretion and normalized plasma AVP levels and kidney AQP-2 mRNA expression in glucocorticoid deficiency $(6,7,12)$.

There is evidence for a gerontological alteration in release of AVP from the posterior pituitary. AVP release 
in response to physiological and pharmacological stimulation is more manifest in elderly subjects compared with younger patients $(13-16)$. Thus the enhanced release of AVP may possibly affect serum $\mathrm{Na}$ levels in a pathological state such as secondary adrenal insufficiency. In the present study, we determined whether aging may play a role in developing hyponatremia in patients with secondary adrenal insufficiency. Also, plasma AVP levels were analyzed in these patients according to the age at which they were diagnosed.

\section{Subjects and methods}

\section{Subjects}

Forty patients with adrenocorticotropin (ACTH)deficient, secondary adrenal insufficiency were examined between January 1985 and December 2000. There were 17 males and 23 females whose ages ranged from 15 to 78 years. They were admitted to the Endocrine and Metabolic Ward of Jichi Medical School Hospital for various reasons closely related to hypopituitarism. Some patients complained of disturbance of consciousness, generalized malaise, nausea or vomiting. Five patients with severe hyponatremia had disturbance of consciousness, including two with semicoma and three with somnolence, but no patient had convulsions. Hyponatremia of less than $135 \mathrm{mmol} / \mathrm{l}$ was initially found in 25 out of 40 patients, which related to the reasons for their admission. The diagnosis of hypopituitarism was initially ascertained in all the patients. Basal levels of pituitary hormones, and tolerance tests for all the pituitary hormones were analyzed, and the impairment in hormonal secretion is shown in Table 1. Isolated ACTH deficiency was found in six subjects, included within brackets in Table 1. Plasma renin activity, plasma aldosterone and AVP levels were determined in association with water and sodium metabolism. The causes of hypopituitarism in the 40 patients were: nine had Sheehan's syndrome, six had autoimmune hypopituitarism, 10 had secondary hypopituitarism due to pituitary tumors, one had hypopituitarism due to hypothalamic disorder, and in 14 patients the cause was not determined. Autoimmune hypophysitis was diagnosed in the patients who had

Table 1 The number of patients who had pituitary hormone deficiency when secondary adrenal insufficiency was diagnosed.

\begin{tabular}{lrrrrrrr}
\hline & $\boldsymbol{n}$ & LH & FSH & GH & TSH & ACTH $^{1}$ & Prolactin \\
\hline Group A & 5 & 4 & 4 & 5 & 1 & $5(0)$ & 1 \\
Group B & 22 & 15 & 15 & 12 & 11 & $22(3)$ & 8 \\
Group C & 13 & 10 & 10 & 7 & 6 & $13(3)$ & 7 \\
\hline
\end{tabular}

The patients were divided into 3 groups according to the age at which diagnosis was ascertained; group A $<20$ years, group B 20-64 years and group $C \geq 65$ years.

1 Number of patients with ACTH deficiency include those with hypopituitarism and isolated ACTH deficiency; number of patients with isolated ACTH deficiency is shown in brackets. positive anti-pituitary antibody, pituitary enlargement closely associated with hypopituitarism which became atropic later, or hypopituitarism during or after pregnancy without any massive hemorrhage. The patients were divided into three groups according to the age at which diagnosis was ascertained. Group A consisted of five patients aged less than 20 years; group B consisted of 22 patients with ages ranging from 20 to 64 years, and group $C$ consisted of 13 patients aged 65 years or older. Although the age limits for the grouping had no scientific reason, patients in group A were around and after adolescence, and those in group $\mathrm{C}$ were elderly patients based on the social definition in Japan.

After completing the diagnosis of hypopituitarism, hormone replacement therapy was started in all patients by administering hydrocortisone and, in part, thyroxine. During follow-up we measured serum electrolytes and plasma AVP levels approximately one month after the start of hydrocortisone replacement.

\section{Measurements}

Blood was collected in chilled tubes containing EDTA$\mathrm{Na}_{2}(1 \mathrm{mg} / \mathrm{ml}$ blood) and centrifuged at 3000 r.p.m. at $4{ }^{\circ} \mathrm{C}$ for $15 \mathrm{~min}$. The supernatants were decanted and frozen at $-20^{\circ} \mathrm{C}$ until assayed for plasma AVP, aldosterone, ACTH and plasma renin activity (PRA). The hormones were measured by RIA. Serum growth hormone $(\mathrm{GH})$, luteinizing hormone $(\mathrm{LH})$, follicle-stimulating hormone (FSH), thyrotropin (TSH), prolactin and cortisol were determined by RIA or enzymatic immunoassay (EIA). All RIAs and EIAs were performed using commercially available kits $(17-21)$, and their intra- and interassay coefficients of variation were, maximally, less than 8.4\%. Plasma osmolality (Posm) and urinary osmolality (Uosm) were measured by freezing-point depression (Model 3W2, Advanced Instruments, Needham Heights, MA, USA). The normal ranges of the parameters measured are: plasma AVP $0.2-2.2 \mathrm{pmol} / \mathrm{l}$, PRA $0.08-0.81 \mathrm{ng} / \mathrm{l}$ in the supine position, plasma aldosterone 30.5$174.8 \mathrm{pmol} / \mathrm{l}$, plasma ACTH $2.0-11.5 \mathrm{pmol} / \mathrm{l}$, serum LH 1.0-38.0 IU/l, serum FSH 2.0-13.3 IU/l, serum prolactin $1.4-14.6 \mu \mathrm{g} / \mathrm{l}$, serum TSH $0.34-3.5 \mathrm{mU} / \mathrm{l}$, and serum cortisol $110.4-504.9 \mathrm{nmol} / \mathrm{l}$.

\section{Statistical analysis}

All values are expressed as means \pm s.E.M. The data were analyzed by an analysis of multiple variance (ANOVA) and Student's $t$-test. A $P$ value less than 0.05 was considered significant.

\section{Results}

Serum $\mathrm{Na}$ and chloride $(\mathrm{Cl})$ levels were 131.9 and $97.5 \mathrm{mmol} / \mathrm{l}$ respectively in all of the patients with secondary adrenal insufficiency who had impaired 
secretion of ACTH. As shown in Table 2 and Fig. 1, hyponatremia was more manifest in the elderly group of patients than in the younger ones, serum $\mathrm{Na}$ levels being $124.7 \pm 2.4 \mathrm{mmol} / \mathrm{l}$ in group C patients. Serum $\mathrm{Na}$ levels were in the normal range in group A patients. There was no difference in serum Na levels between the presence and absence of secondary hypothyroidism (data not shown). Similar results were obtained with Posm and serum $\mathrm{Cl}$ levels. However, serum potassium (K) levels were within the normal range, and were not different among the three groups of patients. In addition, systolic blood pressure were significantly elevated according to age.

Figure 2 shows the relationship between serum $\mathrm{Na}$ levels and age in patients with secondary adrenal insufficiency. There was a negative correlation between serum Na levels and age $(r=-0.681, P<0.0001)$.

Following our definition in the present study, ACTH deficiency was found in all of the patients with secondary adrenal insufficiency. Plasma ACTH levels were low-normal in each group, while serum cortisol levels were significantly decreased in all three groups of patients (Table 3). PRA was reduced according to the patients' age, being significantly less in group $\mathrm{C}$ patients than in those of group A. However, plasma aldosterone levels were comparable among the three groups of patients.

Plasma AVP levels in patients with secondary adrenal insufficiency are shown in Fig. 3. When compared among the three groups of patients, plasma AVP levels seemed to distribute at the relatively high level, although this was not statistically significant. Figure 4 shows the relationship between Posm and plasma AVP levels in patients with secondary adrenal insufficiency and in controls. The elevation of plasma AVP was apparent in the elderly group, since plasma AVP levels seemed likely to be high as compared with the respective hypo-osmolality in plasma. Such an alteration was less clear in the group $\mathrm{B}$ patients, and was not found in those of group A.

The alteration in serum Na and plasma AVP levels after the start of hydrocortisone replacement is shown in Table 4. After the completion of diagnosis, hydrocortisone replacement $(20-30 \mathrm{mg}$ per day) was started and serum $\mathrm{Na}$ levels were normalized (increased from $124.7 \pm 2.4$ to $141.7 \pm 2.6 \mathrm{mmol} / \mathrm{l}$ ) in approximately one month in the group $\mathrm{C}$ patients. The treatment also reduced plasma AVP levels from $1.7 \pm 0.3$ to $0.9 \pm 0.2 \mathrm{pmol} / \mathrm{l}$ in the group $\mathrm{C}$ patients $(P<0.01)$, a value comparable to the respective Posm. Similarly, serum $\mathrm{Na}$ levels were increased in the group B patients, but there was no significant change in plasma AVP levels.

\section{Discussion}

The present study demonstrated marked hyponatremia of less than $125 \mathrm{mmol} / \mathrm{l}$ in the elderly patients aged 65

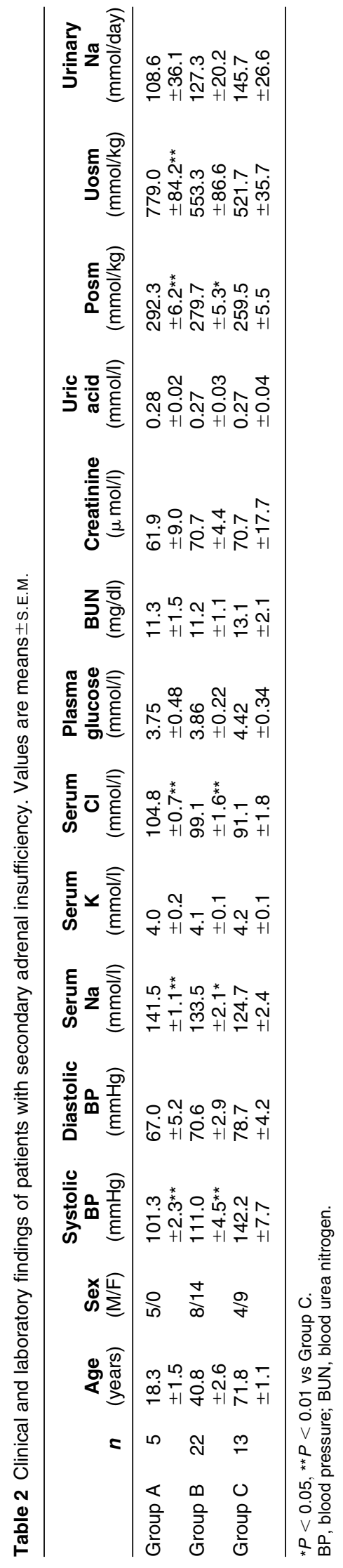




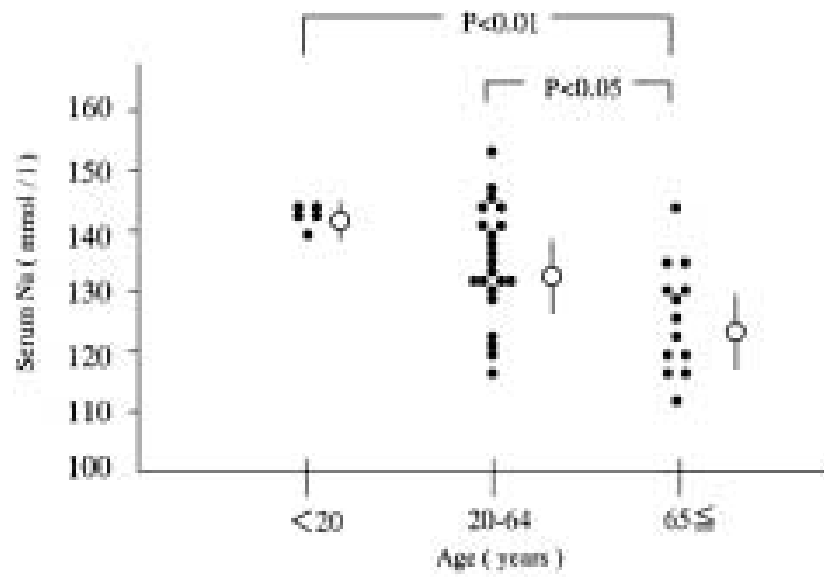

Figure 1 Serum $\mathrm{Na}$ levels in the three groups of patients with secondary adrenal insufficiency. The patients were divided into 3 groups according to the age at which diagnosis was ascertained: group $A<20$ years, group $B 20-64$ years, and group $C \geq 65$ years. Means \pm S.E.M. are represented by the open circles.

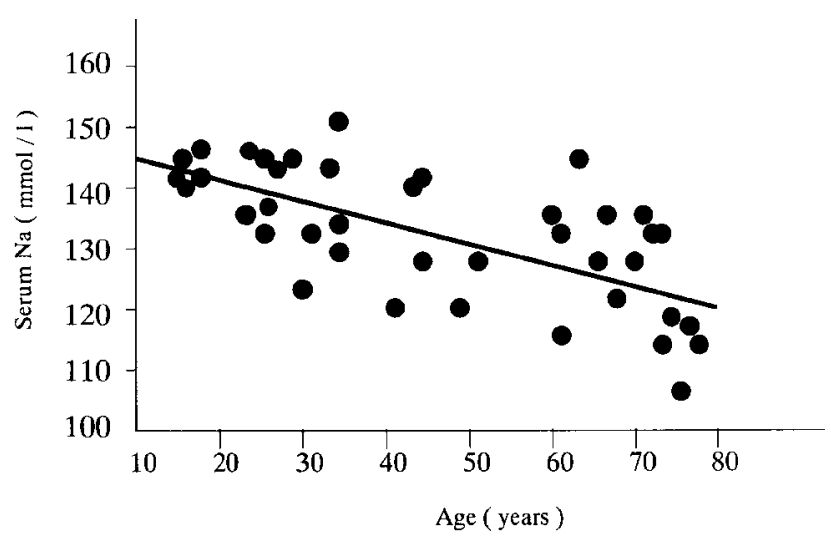

Figure 2 Relationship between serum $\mathrm{Na}$ levels and age in patients with secondary adrenal insufficiency. There was a negative correlation between serum $\mathrm{Na}$ levels and age $(r=-0.681$, $P<0.0001)$.

years or older with secondary adrenal insufficiency. Hyponatremia was progressively exaggerated as the patients grew older. There are several factors that could be involved in the mechanisms for hyponatremia: enhanced secretion of AVP, attenuated renal handling of $\mathrm{Na}$, decreased intake of $\mathrm{Na}$, change in water intake, and others. Enhanced secretion of AVP is closely involved in the mechanism for impaired water excretion and hyponatremia in hypopituitarism, particularly hypofunction of the pituitary and adrenocortical axis $(3,9,10)$. In experimental models of glucocorticoid deficiency non-suppressible release of AVP is found despite hypo-osmolality, which should suppress AVP release to undetectable levels $(5-7)$. We have demonstrated that the AVP $V_{2}$ receptor antagonist blocked the upregulation of AQP-2 mRNA expression and promptly normalized renal water excretion in glucocorticoid-deficient rats (12). Also, similar results were obtained with hydrocortisone replacement in glucocorticoid-deficient rats and patients with hypopituitarism, i.e. hydrocortisone replacement normalizes AVP secretion, urinary excretion of AQP-2 and water diuresis $(4,6,9,10,12,22)$. Therefore, non-suppressible secretion of AVP plays a crucial role in impaired water excretion in secondary adrenal insufficiency.

Urinary excretion of $\mathrm{Na}$ was more than $100 \mathrm{mmol} /$ day in the three groups of patients. It seemed likely to be increased in the group A patients as compared with such a hyponatremic state in the group B and $\mathrm{C}$ patients. Although low PRA was found in the elderly group, plasma aldosterone remained normal. Serum cortisol levels were reduced in secondary adrenal insufficiency, but there was no difference in serum cortisol levels among the three groups. Therefore, the derangement in adrenocortical hormones had little effect on enhanced urinary $\mathrm{Na}$ excretion (23, 24). Rather, renal $\mathrm{Na}$ handling per se is attenuated in the elderly subjects (15), and this factor could be associated with the elevation of urinary $\mathrm{Na}$ excretion in the elderly group with secondary adrenal insufficiency.

Increased release of AVP could be the primary factor for producing severe hyponatremia in the elderly patients with secondary adrenal insufficiency. As shown in Fig. 4, it is clear that plasma AVP levels were relatively high compared with the respective hypo-osmotic state in the elderly group. In this regard, our previous study found that there is significantly more augmentation in AVP release in response to the osmotic and non-osmotic stimuli in elderly subjects than in young subjects (15). Similarly, such a gerontological alteration in the release of AVP was also reported by other investigators $(13,14,16)$. Thus, aging per se enhances the physiological release

Table 3 PRA, aldosterone, ACTH and cortisol in three groups of patients with secondary adrenal insufficiency. Values are means \pm S.E.M.

\begin{tabular}{|c|c|c|c|c|c|}
\hline & $n$ & PRA (ng/l/s) & Aldosterone (pmol/l) & ACTH $(\mathrm{pmol} / \mathrm{l})$ & Cortisol (nmol/l) \\
\hline Group A & 5 & $0.39 \pm 0.08^{\star}$ & $79.1 \pm 34.7$ & $2.73 \pm 0.62$ & $66.2 \pm 19.3$ \\
\hline Group B & 21 & $0.42 \pm 0.14$ & $133.4 \pm 36.3$ & $2.75 \pm 0.53$ & $93.8 \pm 27.6$ \\
\hline Group C & 12 & $0.14 \pm 0.06$ & $87.1 \pm 19.9$ & $3.33 \pm 0.53$ & $121.4 \pm 22.1$ \\
\hline Normal values & & $0.08 \sim 0.81$ & $30.5 \sim 174.8$ & $2.0 \sim 11.5$ & $110.4 \sim 504.9$ \\
\hline
\end{tabular}

* $P<0.05$ vs Group C. 


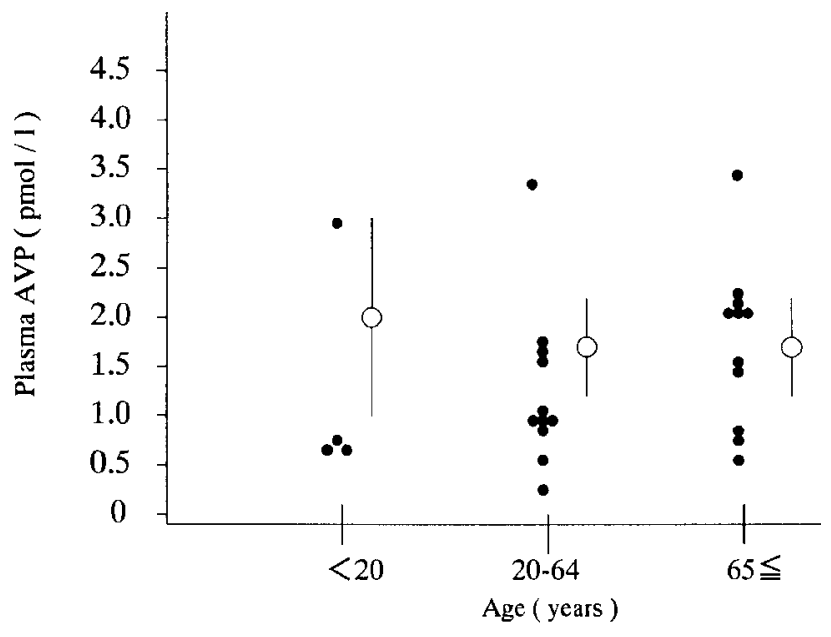

Figure 3 Plasma AVP levels in the three groups of patients with secondary adrenal insufficiency. Means \pm S.E.M. are represented by the open circles.

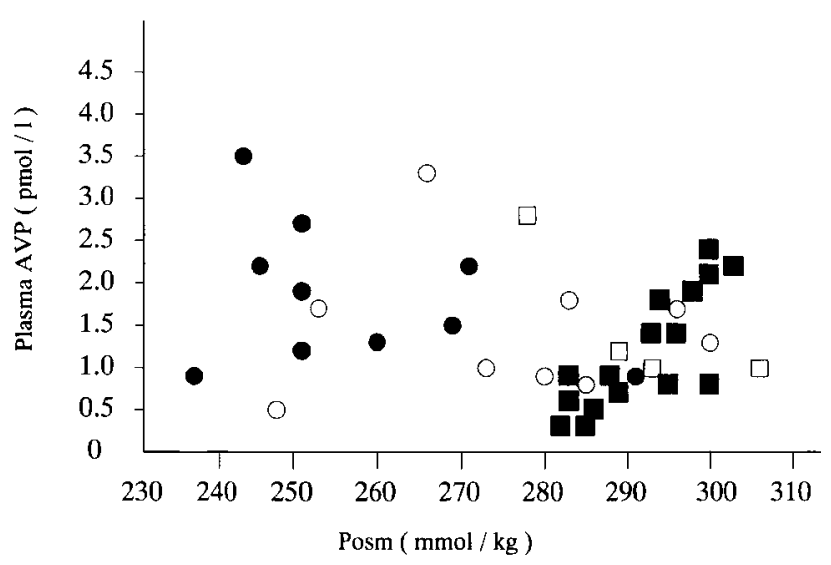

Figure 4 Relationship between plasma osmolality (Posm) and plasma AVP levels in patients with secondary adrenal insufficiency and in control subjects. ( $\square$ ) Group A patients (aged $<20$ years), (O) group B patients (aged 20-64 years), $(\bullet)$ group $C$ patients (aged $\geq 65$ years), (ם) control subjects.

of AVP from the neurohypophysis. In addition, nausea or vomiting could cause non-osmotic AVP release via the area postrema (25). However, as there were few patients who exhibited nausea or vomiting, these effects

Table 4 Alternations in serum sodium and plasma AVP levels before and after hydrocortisone treatment. Values are means \pm S.E.M.

\begin{tabular}{|c|c|c|c|c|c|c|c|c|}
\hline & \multicolumn{4}{|c|}{ Serum Na (mmol/l) } & \multicolumn{4}{|c|}{ Plasma AVP (pmol/l) } \\
\hline & Before & $n$ & After & $n$ & Before & $n$ & After & $\bar{n}$ \\
\hline & 142 & 5 & 143.0 & & & & 1.9 & \\
\hline & $132.3 \pm 2.1$ & 22 & 1103 & 15 & & 9 & & \\
\hline Grous & $124.7 \pm 2.4$ & 13 & $141.7 \pm 2.6^{*}$ & * 13 & $1.7 \pm 0.3$ & 10 & $0.9 \pm 0.2^{\star *}$ & \\
\hline
\end{tabular}

${ }^{\star} P<0.01,{ }^{* \star} P<0.05$ vs before treatment. should be of little value in causing the non-osmotic release of AVP in the present study. The follow-up study with hydrocortisone replacement in the elderly patients showed that serum $\mathrm{Na}$ levels increased by $17 \mathrm{mmol} / \mathrm{l}$ (mean) during the observation period of approximately one month. Also, plasma AVP levels were normalized after hydrocortisone replacement. In addition, urinary excretion of AQP-2, which has a close correlation with plasma AVP levels in normal subjects (26), was promptly reduced from $352.8 \pm 53.6$ to $190.8 \pm 25.1 \mathrm{fmol} / \mathrm{mg}$ creatinine in the elderly patients with secondary adrenal insufficiency $(n=8)(1)$. Unfortunately, urinary excretion of AQP-2 could not be evaluated statistically in the other two groups of patients as not enough data were available.

In conclusion, the present study demonstrated that hyponatremia was progressively exaggerated in the patients with secondary adrenal insufficiency as they grew older. Enhanced secretion of AVP was also evident in the elderly patients, and was closely involved in the mechanism for impaired water excretion and hyponatremia in hypopituitarism, particularly hypofunction of the pituitary and adrenocortical axis. Hydrocortisone replacement stopped the AVP-dependent water retention and normalized serum Na levels. These results indicate that non-suppressible release of AVP is crucially involved in the impaired water excretion and hyponatremia in the elderly subjects with secondary adrenal insufficiency as compared with the younger patients.

\section{Acknowledgements}

The study was partly supported by grants from the Ministry of Education, Science and Culture of Japan (no. 12770619, no. 13671160 and no. 13137208). The present study was presented at the 83rd Annual Meeting of The Endocrine Society, June 20-23 2001, Denver, Colorado, USA.

\section{References}

1 Ishikawa S, Saito T, Fukagawa A, Higashiyama M, Nakamura T, Kusaka I et al. Close association of urinary excretion of aquaporin-2 with appropriate and inappropriate arginine vasopressin-dependent antidiuresis in hyponatremia in elderly subjects. Journal of Clinical Endocrinology and Metabolism $2001 \mathbf{8 6}$ 1665-1671.

2 Slessor A. Studies concerning the mechanism of water retention in Addison's disease and in hypopituitarism. Journal of Clinical Endocrinology $195111700-723$.

3 Amhed AB, George BC, Gonzalez-Auvert T \& Dingman JF. Increased plasma arginine vasopressin in clinical adrenocortical insufficiency and its inhibition of glucocorticoids. Journal of Clinical Investigation $196746111-123$

4 Green HH, Harrington AR \& Valtin H. On the role of antidiuretic hormone in the inhibition of acute water diuresis in adrenal insufficiency and the effects of gluco- and mineralocorticoids in reversing the inhibition. Journal of Clinical Investigation $1970 \mathbf{4 9}$ $1724-1736$ 
5 Seif SM, Robinson AG, Zimmerman EA \& Wilkins J. Plasma neurophysin and vasopressin in the rat: response to adrenalectomy and steroid replacement. Endocrinology 1978103 1009-1015.

6 Ishikawa S \& Schrier RW. Effect of arginine vasopressin antagonist on renal water excretion in glucocorticoid and mineralocorticoid deficient rats. Kidney International 198222 587-593.

7 Linas SL, Berl T, Robertson GL, Aisenbrey GA, Schrier RW \& Anderson RJ. Role of vasopressin in the impaired water excretion of glucocorticoid deficiency. Kidney International 198018 58-67.

8 Robinson AG, Seif SM, Verbalis JG \& Brownstein MJ. Quantitation of changes in the content of neurohypophyseal peptides in hypothalamic nuclei after adrenalectomy. Neuroendocrinology 198336 347-350.

9 Ishikawa S, Fujisawa G, Tsuboi Y, Okada K, Kuzuya T \& Saito T. Role of antidiuretic hormone in hyponatremia in patients with isolated adrenocorticotropic hormone deficiency. Endocrinologia Japonica 199138 325-330.

10 Kamoi K, Tamura T, Tanaka K, Ishibashi M \& Yamaji T. Hyponatremia and osmoregulation of thirst and vasopressin secretion in patients with adrenal insufficiency. Journal of Clinical Endocrinology and Metabolism 199377 1584-1588.

11 Schrier RW, Berl T \& Anderson RJ. Osmotic and nonosmotic control of vasopressin release. American Journal of Physiology 1979 236 F321-F332.

12 Saito T, Ishikawa S, Ando F, Higashiyama M, Nagasaka S, Sasaki S et al. Vasopressin-dependent upregulation of aquaporin-2 gene expression in glucocorticoid-deficient rats. American Journal of Physiology 2000279 F502-F508.

13 Helderman JH, Vestal RE, Rowe JW, Tobin JD, Andres R \& Robertson GL. The response of arginine vasopressin to intravenous ethanol and hypertonic saline in man: the impact of aging. Journal of Gerontology 197833 39-47.

14 Goldstein CS, Braunstein S \& Goldfarb B. Idiopathic syndrome of inappropriate antidiuretic hormone secretion possibly related to age. Annals of Internal Medicine 198399 185-188.

15 Ishikawa S, Fujita N, Fujisawa G, Tsuboi Y, Sakuma N, Okada K et al. Involvement of arginine vasopressin and renal sodium handling in pathogenesis of hyponatremia in elderly patients. Endocrine Journal $199643101-108$.

16 Chiodera P, Volpi R, Pilla S, Cataldo S, Capretti L \& Coiro V. Effect of aging on the arginine vasopressin response to physostigmine and angiotensin II in normal men. Journal of Investigative Medicine 200048 203-206.

17 Ishikawa S, Saito T, Okada K, Tsutsui K \& Kuzuya T. Effect of vasopressin antagonist on water excretion in inferior vena cava constriction. Kidney International 198630 49-55.

18 Krieger DT \& Allen W. Relationship of bioassayable and immunoassayable plasma ACTH and cortisol concentration in normal subjects and in patients with Cushing's disease. Journal of Clinical Endocrinology and Metabolism 197540 675-687.

19 Ogihara T, Kumahara Y \& Yamamoto T. Measurement of angiotensin II. Clinical Science 19728 1071-1076.

20 Ogihara T, Iinuma K, Nishi K, Arakawa Y, Takagi A, Kurata K et al. A non-chromatographic non-extraction radioimmunoassay for serum aldosterone. Journal of Clinical Endocrinology and Metabolism 197745 726-731.

21 Gibiki K, Iinuma F, Nomura K, Kasahara J, Demura R \& Demura H. A method of radioimmunoassay of plasma cortisol. Clinical Endocrinology 198028 1127-1132.

22 Saito T, Ishikawa S, Ando F, Okada N, Nakamura T, Kusaka I et al. Exaggerated urinary excretion of aquaporin-2 in the pathological state of impaired water excretion dependent upon arginine vasopressin. Journal of Clinical Endocrinology and Metabolism $1998 \mathbf{8 3}$ 4034-4040.

23 Crane MG \& Harris JJ. Effect of aging on renin activity and aldosterone secretion. Journal of Laboratory and Clinical Medicine 1976 87 947-959.

24 Zadik Z \& Kowarski AA. Normal integrated concentration of aldosterone and plasma renin activity: effect of age. Journal of Clinical Endocrinology and Metabolism 198050 867-869.

25 Robertson GL. The regulation of vasopressin function in health and disease. Recent Progress in Hormone Research 197723 333-385.

26 Saito T, Ishikawa S, Sasaki S, Nakamura T, Rokkaku K, Kawakami A et al. Urinary excretion of aquaporin-2 in the diagnosis of central diabetes insipidus. Journal of Clinical Endocrinology and Metabolism 199782 1823-1827.

Received 31 July 2002

Accepted 12 November 2002 